\title{
Research on Parameter Distribution Features of Photovoltaic Array under the Cover and Shadow Shading Conditions
}

\author{
Honglu Zhu, ${ }^{1,2}$ Cao Yu, ${ }^{2,3}$ Lingxing Lu, ${ }^{2}$ Weiwei Lian, ${ }^{2}$ Jianxi Yao $\mathbb{D}^{1},{ }^{1,2}$ and Yang Hu $\mathbb{D}^{1}$ \\ ${ }^{1}$ State Key Laboratory of Alternate Electrical Power System with Renewable Energy Sources, North China Electric Power University, \\ Changping District, Beijing, China \\ ${ }^{2}$ School of Renewable Energy, North China Electric Power University, Changping District, Beijing, China \\ ${ }^{3}$ China Three Gorges New Energy Co., Ltd, Beijing, China
}

Correspondence should be addressed to Yang Hu; hooyoung@ncepu.edu.cn

Received 19 April 2018; Accepted 5 July 2018; Published 6 August 2018

Academic Editor: Jegadesan Subbiah

Copyright (C) 2018 Honglu Zhu et al. This is an open access article distributed under the Creative Commons Attribution License, which permits unrestricted use, distribution, and reproduction in any medium, provided the original work is properly cited.

\begin{abstract}
The outdoor operating photovoltaic arrays have two different shading conditions, shadowing and covering. The shading causes a decrease in output power of photovoltaic system and may bring hot spots which causes physical damage to the array. This paper studies the electrical parameter distribution feature of photovoltaic array under different shading conditions by means of analog simulation and empirical testing. Through introducing theoretical computational method of the electrical parameters, it describes the distribution features of the electrical parameters of photovoltaic array. The results indicate that the influence of local shadowing on the current of array can be neglected. Shadowing decreases the optimal operating voltage while covering leads to a decrease in the optimal operating voltage and the open-circuit voltage. The drop magnitude of voltage is associated with the number of the shaded cell strings and the string voltage. The two shading types can be identified on the basis of distribution rules of open-circuit voltage and optimal operating voltage. Simulations and experiments verify the consistency of the rules. Relevant conclusions provide a reference for modeling, online fault diagnosis, and optimization design of the maximum power tracking algorithm of photovoltaic array under different shading conditions.
\end{abstract}

\section{Introduction}

As the most important method for solar energy utilization, photovoltaic power generation is developing rapidly. With the world cumulative photovoltaic (PV) installed capacity of up to $390 \mathrm{GWp}$ in 2017, PV power generation plays an increasingly important role in the energy supply structure. In actual operation, $\mathrm{PV}$ arrays are usually distributed in a very large region due to their low power density. Therefore, shadowing from the front and rear rows of photovoltaic array is often inevitable due to the restriction of floor space. Meanwhile, photovoltaic arrays are mostly shaded by tall buildings, tall trees, fallen leaves, and birds' droppings. It is common that the photovoltaic arrays usually operate under different shading conditions $[1,2]$. The temporary shadowing of PV arrays will lead to a decrease in array efficiency, increased power loss, and more complex output characteristics. The prolonged covering can cause excessively high local temperature, hot spots, and breakdown phenomenon, which adversely influence the output efficiency and service life of the PV modules $[3,4]$. Therefore, the good understanding of electrical parameter transfer law of PV arrays under different shading conditions is significant for the performance assessment, fault diagnosis, and optimal operation of the photovoltaic power station.

At present, scholars both locally and abroad are conducting series of simulations and experimental studies on the output characteristics of the PV modules/arrays under shading conditions. In [5-7], MATLAB-Simulink is used to establish a simulation model of photovoltaic array under the shadowing condition and concluded that the output of the PV array exhibits a multipeak and stepped shape under the shadow condition. In [8], it is concluded that hot spots occur when the short-circuit current of the photovoltaic cells is smaller than the electric current flowing through the cells based on the simulations and experimental studies of the reverse 


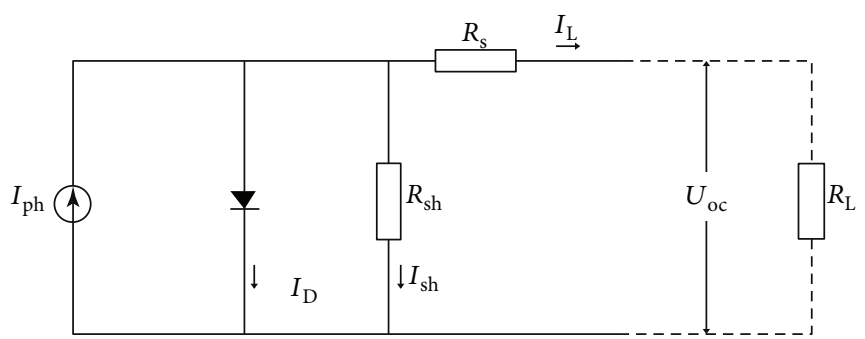

Figure 1: Equivalent circuit of the photovoltaic cell.

Bishop model of photovoltaic arrays. In $[9,10]$, it is concluded that the loss of the output power increases as the shading area increases and the more the cell strings are shaded, the greater the power loss under the same area is. In [11], it is pointed out that the conventional maximum power point tracking (MPPT) algorithms (such as the conductance increment method and the disturbance observation method) are susceptible to failure due to the local extreme point under the shadowing condition. In [12-14], some improved MPPT algorithms are proposed to raise the output efficiency of the photovoltaic array under the shadowing condition. In actual engineering, PV arrays may be subjected to two types of shading, that is, the shadow shading arising from tall buildings and the front and rear rows of array and the cover shading arising from objects such as fallen leaves and dust. In the above literature, however, only the output properties of photovoltaic array under the shadow condition by means of simulation or experiment are studied but no theoretical analyses or experimental studies are conducted on the cover shading. It is impossible to systematically describe the distribution rules of electrical parameters of photovoltaic array in actual operation. A research on the output characteristics and the rules of electrical parameter distribution of photovoltaic array under different shading conditions is therefore has significant theoretical and engineering application.

To illustrate the output characteristics and the electrical parameter distribution feature of photovoltaic array under the shadow and cover conditions, the paper first presents mathematical description of photovoltaic cells, modules, and arrays and establishes the appropriate Simulink model. Designing simulation experiments under the two shading conditions and discussing the theoretical maximum power point voltage and current as the contrasting parameters for empirical testing were considered in this study. Comparing the theoretical results with experimental results concludes the rules of electrical parameter distribution of the photovoltaic array under various shading conditions. The simulation results coincide with the empirical testing results.

\section{Mathematical Models of Photovoltaic Cells, Modules, and Array}

2.1. Equivalent Circuit Model of Photovoltaic Cells. Photovoltaic cell converts the luminous energy into electrical energy through the photovoltaic effect. The analysis process of this paper is based on the equivalent circuit of the photovoltaic cell of the monolithic diode model as shown in Figure 1, where $I_{\mathrm{ph}}$ is the photogenerated current, $I_{\mathrm{D}}$ is diode current, $I_{\text {sh }}$ is parallel current, $I_{\mathrm{L}}$ is output current, $R_{\mathrm{sh}}$ is parallel resistance, $R_{\mathrm{s}}$ is series resistance, and $R_{\mathrm{L}}$ is external load.

The voltage-current equation can be expressed as follows:

$$
I_{\mathrm{L}}=I_{\mathrm{ph}}-I_{0}\left\{\exp \left[\frac{q\left(U+R_{\mathrm{s}} I\right)}{A K T}\right]-1\right\}-\frac{U+R_{\mathrm{s}} I}{R_{\mathrm{sh}}}
$$

where $I_{0}$ is reverse saturation current of diode, $q$ is electron charge $\left(1.602 \times 10^{-19} \mathrm{C}\right), A$ is ideal coefficient of diode, and $K$ is Boltzmann constant $\left(1.38 \times 10^{-23} \mathrm{~J} / \mathrm{K}\right)$.

The photogenerated current $I_{\mathrm{ph}}$ can be considered to approximate the short-circuit current of photovoltaic cell $I_{\mathrm{sc}}$, and the tail term $\left(U+R_{\mathrm{s}} I\right) / R_{\mathrm{sh}}$ can be ignored; hence, it is much smaller than that of the short-circuit current. Equation (1) therefore can be rewritten as follows:

$$
I_{\mathrm{L}}=I_{\mathrm{sc}}\left(1-C_{1}\left(\exp \left(\frac{U}{C_{2} U_{\text {oc }}}\right)-1\right)\right),
$$

where $C_{1}$ and $C_{2}$ are the definition coefficients. In case of maximum power point $\left(I=I_{\mathrm{m}}, U=U_{\mathrm{m}}\right)$ and open-circuit voltage $\left(I=0, U=U_{\mathrm{oc}}\right)$ in (2), we can obtain

$$
\begin{gathered}
\mathrm{C}_{1}=\left[\frac{\left(I_{\mathrm{sc}}-I_{\mathrm{m}}\right)}{I_{\mathrm{sc}}}\right] * \exp \left[\frac{-U_{\mathrm{m}}}{\left(C_{2} * U_{\mathrm{oc}}\right)}\right], \\
C_{2}=\frac{\left(U_{\mathrm{m}} / U_{\mathrm{oc}}-1\right)}{\ln \left(1-I_{\mathrm{m}} / I_{\mathrm{sc}}\right)} .
\end{gathered}
$$

External operating environment is not considered in the external behavioral characteristics of the photovoltaic cells described in (2), (3), and (4). However, the output of the photovoltaic modules is primarily influenced by solar irradiance and temperature. Therefore, it is necessary to consider the changes in solar irradiance and temperature during the process of photovoltaic module simulation as below [15]:

$$
\begin{aligned}
I_{\mathrm{sc}} & =I_{\text {scref }}\left[1+a\left(T-T_{\mathrm{ref}}\right)\right] \cdot \frac{S}{S_{\text {ref }}}, \\
U_{\mathrm{oc}} & =U_{\text {ocref }}\left[1-c\left(T-T_{\mathrm{ref}}\right)\right] \ln \left[e+b\left(\frac{S}{S_{\text {ref }}}-1\right)\right], \\
I_{\mathrm{m}} & =I_{\mathrm{mref}}\left[1+a\left(T-T_{\mathrm{ref}}\right)\right] \cdot \frac{S}{S_{\mathrm{ref}}} \\
U_{\mathrm{m}} & =U_{\text {mref }}\left[1-c\left(T-T_{\mathrm{ref}}\right)\right] \ln \left[e+b\left(\frac{S}{S_{\text {ref }}}-1\right)\right],
\end{aligned}
$$




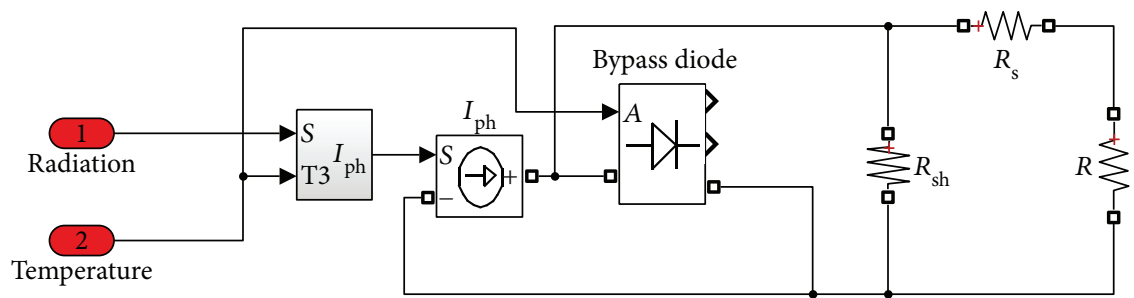

FIGURE 2: Simulink model of photovoltaic cells.

where $S$ and $S_{\text {ref }}$ are the solar irradiance received by photovoltaic cells and solar irradiance under standard conditions, respectively, $T$ and $T_{\text {ref }}$ are actual temperature and temperature of photovoltaic cells under standard conditions, respectively, and $a, b$, and $c$ are correction coefficients, where $a=0.0008 /{ }^{\circ} \mathrm{C}, b=0.2$, and $c=0.002 /{ }^{\circ} \mathrm{C}$.

Equations (5), (6), (7), and (8) describe the distribution features of theoretical short-circuit current, opencircuit voltage, and voltage and current at optimal operating point of photovoltaic cells under different solar irradiances and temperatures. The electrical parameters of photovoltaic array under different shading conditions are analyzed using (5), (6), (7), and (8) in the subsequent experimental process.

Based on the above mathematical model, the simulation model is established for photovoltaic cells as shown in Figure 2. There are two inputs, irradiance, and temperature. The photogenerated current $I_{\mathrm{ph}}$ does not change with the operative mode of photovoltaic cells when the irradiation intensity is constant. A constant current source $I_{\mathrm{ph}}$ is therefore used for simulation. The circuit also includes bypass diode, parallel resistance $R_{\mathrm{sh}}$, and series resistance $R_{\mathrm{s}}$, where $R$ is the output load.

2.2. Model of Photovoltaic Modules and Array. The current and voltage generated by a single photovoltaic cell are not enough for the load. Generally, many photovoltaic cells are connected in series or in parallel to create a photovoltaic module [16]. In a photovoltaic power station, several modules are connected in series or in parallel. The modules and arrays might be connected in a way as shown in Figure 3.

It is assumed that the number of cells in series in the photovoltaic module is $n$ and the number of cells in parallel is $m$. Then, the parameters of the photovoltaic module may be expressed as follows:

$$
\begin{aligned}
U_{\text {oc-module }} & =n \cdot U_{\mathrm{oc}} \\
U_{\text {m-module }} & =n \cdot U_{\mathrm{m}}, \\
U_{\text {module }} & =n \cdot U, \\
I_{\text {sc-module }} & =m \cdot I_{\mathrm{sc}} \\
I_{\mathrm{m} \text {-module }} & =m \cdot I_{\mathrm{m}}, \\
I_{\text {module }} & =m \cdot I .
\end{aligned}
$$

It is assumed that the photovoltaic array comprises of $N$ photovoltaic modules in series and $M$ photovoltaic modules in parallel. Then, we can obtain

$$
\begin{aligned}
R_{\text {s-array }} & =\frac{N}{M} \cdot R_{\text {s-module}}, \\
R_{\text {sh-array }} & =\frac{N}{M} \cdot R_{\text {sh-module }}, \\
I_{\text {sc-array }} & =M \cdot I_{\mathrm{sc}}, \\
I_{\text {array }} & =M \cdot I, \\
I_{\mathrm{m} \text {-array }} & =M \cdot I_{\mathrm{m}}, \\
U_{\text {oc-array }} & =N \cdot I_{\text {oc-module }} \\
U_{\text {array }} & =N \cdot I_{\text {module }} \\
U_{\text {m-array }} & =N \cdot U_{\text {m-module }}
\end{aligned}
$$

The simulation model of the cells is encapsulated, and the appropriate parameters are set to obtain the simulation model of the modules. The modules are connected in series and parallel to create a photovoltaic array. Figure 4 presents the simulation model of a $N \times$ $M$ photovoltaic array. A $1 \times 3$ photovoltaic array was used in the simulations and experiments for the next analysis simplicity.

2.3. Output Characteristics of Modules. A typical $245 \mathrm{~W}$ module is used for the analysis in the paper. The cell connection within the module and the module parameters are shown in Table 1 and Figure 5.

The simulation model is established for the modules according to (9). The output characteristics of the modules under typical temperature and light conditions are shown in Figure 6.

Figure 6 shows that photovoltaic module is a nonlinear direct-current power source instead of a constant voltage source or a constant current source. Its output current approximates a constant one under most operating voltages. The current declines sharply as it approaches opencircuit voltage point. The red line in the figure denotes the variation trend of the optimal operating point with change in solar irradiance and temperature. It can be seen from (a) and (b) that the current parameters of photovoltaic modules are directly proportional to irradiance at a fixed temperature. An increase in irradiance leads to an increase in short-circuit current and current at optimal operating point, but the effect of the irradiance on the 


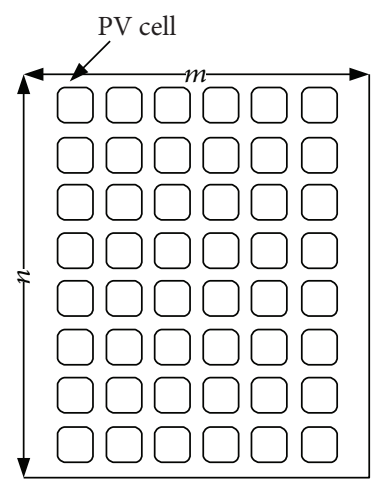

(a)

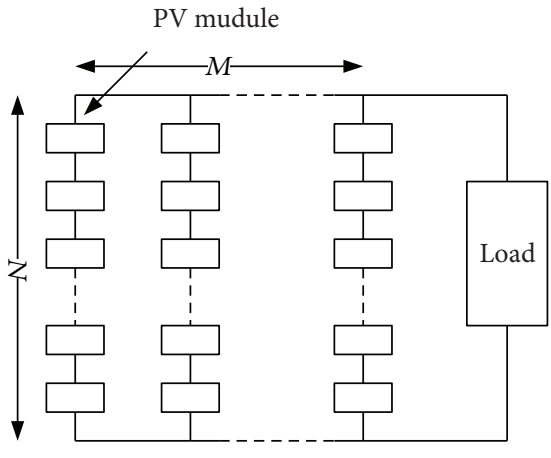

(b)

FIgURE 3: (a) Schematic diagram for photovoltaic module. (b) Schematic diagram for photovoltaic array.

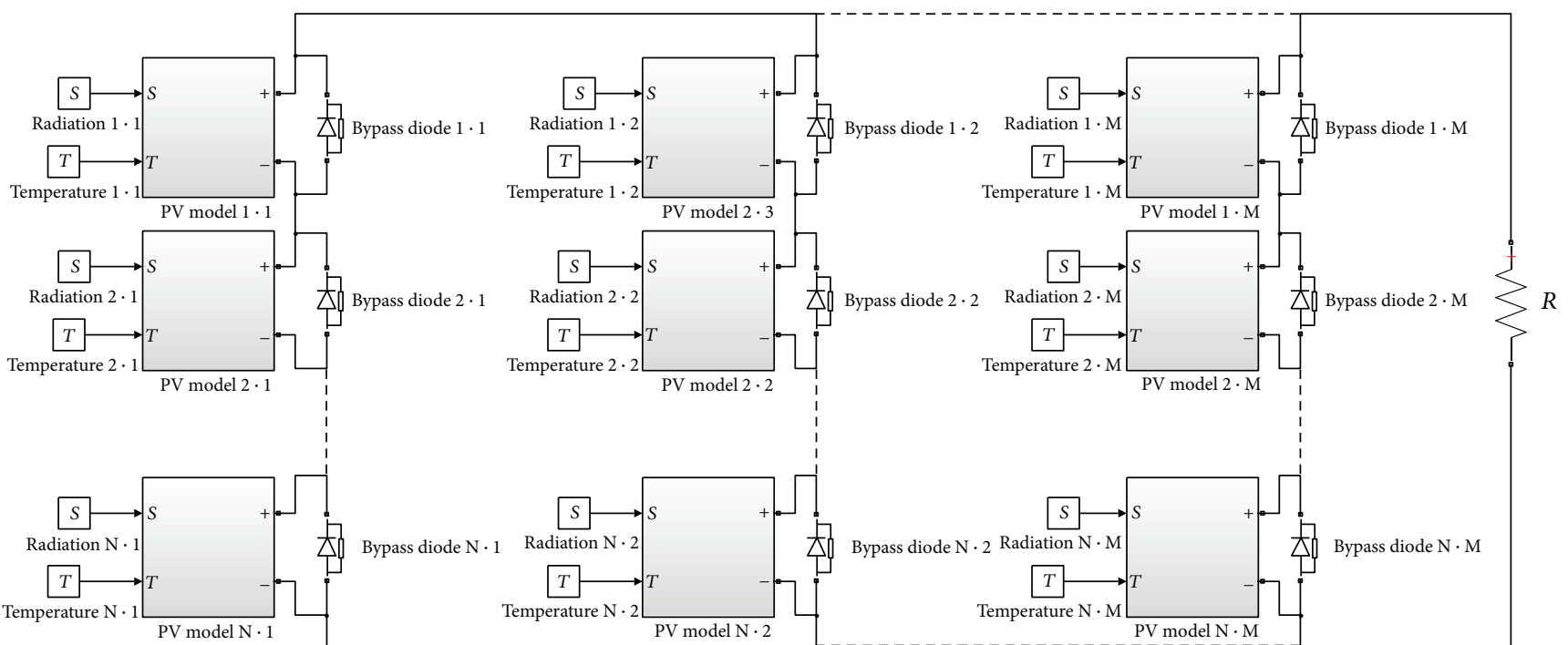

FIGURE 4: Simulation model of photovoltaic array. By entering different temperatures and irradiance, we can get the IV/PV curves of PV arrays under different operating conditions.

TABLE 1: Basic parameters for the module.

\begin{tabular}{lcc}
\hline Parameter & Variable & Value \\
\hline Maximum power & $P_{\mathrm{m}}$ & $245(\mathrm{~W})$ \\
Optimum operating voltage & $V_{\mathrm{m}}$ & $30.1(\mathrm{~V})$ \\
Optimum operating current & $I_{\mathrm{m}}$ & $8.14(\mathrm{~A})$ \\
Open-circuit voltage & $U_{\mathrm{oc}}$ & $37.5(\mathrm{~V})$ \\
Short-circuit current & $I_{\mathrm{sc}}$ & $8.76(\mathrm{~A})$ \\
Temperature coefficient of $I_{\mathrm{sc}}$ & $\alpha$ & $0.06\left(\% /{ }^{\circ} \mathrm{C}\right)$ \\
Temperature coefficient of $V_{\mathrm{oc}}$ & $\beta$ & $-0.31\left(\% /{ }^{\circ} \mathrm{C}\right)$ \\
\hline
\end{tabular}

Specific parameters of photovoltaic module.

open-circuit voltage and the optimal operating voltage is minimal. It can be seen from (c) and (d) that the voltage and temperature parameters of the photovoltaic module are inversely proportional. A lower temperature leads to a higher open-circuit voltage and a higher optimal operating voltage, but the effect of temperature on the short-circuit current and the current at the optimal operating point is little and insignificant. The relationship between various electrical parameters of photovoltaic modules, irradiance, and temperature is specifically described in (5), (6), (7), and (8).

\section{Simulation of the Output Features of Photovoltaic Array under Various Shading Conditions}

The shading of a photovoltaic array which working in outdoor can be classified into two, one is the shadow shading, arising from the surrounding buildings or the front and rear rows of the arrays. Such shading moves with sun position causing no physical damage to the photovoltaic modules or arrays, and the direct radiation received by the shadowed cells decreases substantially but small 


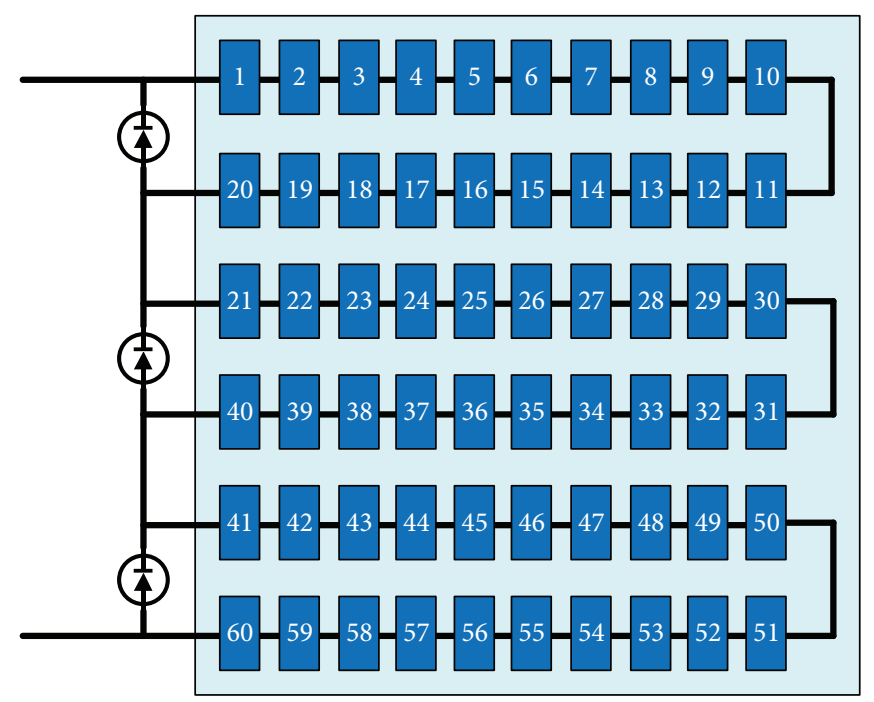

Figure 5: Internal wiring diagram for the module. The module consists of 60 cells in series.

amount of scattered radiation being absorbed. In simulation, the irradiation intensity of the shadowed photovoltaic modules is set at $15 \%$ of the irradiation intensity absorbed by the unshadowed modules [17]. Cover shading, on the other hand, refers to that arising from direct covering of the array surface by objects like leaves and falling products. In such a case, the irradiation intensity received by the covered cells approximates to zero. Such shading has often a fixed position and causes permanent hot spots which jeopardizes the safe operation of photovoltaic array if not identified in time. In simulation, the solar irradiation intensity of such shading is set at zero. Different shading types and the setting of shading conditions are shown in Figure 7 and Table 2.

3.1. Shadow Shading. The simulation results under the shadow conditions are shown in Figure 8. Shadowing leads to nonuniform irradiation received by the array, and the output presents multiple peaks and ladder-like features. Shadows 1, 2, and 4 have consistent output characteristics. Similarly, shadows 3 and 5 are consistent. The output characteristics decrease in a ladder manner from shadow 4 to shadow 6. Table 3 lists the distribution of the electrical parameters of the array under different shadowing conditions. The open-circuit voltage $U_{\text {oc }}$ and short-circuit current $I_{\text {sc }}$ change a little, but the electrical parameters of the optimal operating point vary regularly.

According to Table 3, from shadow 4 to shadow 6 , shading leads to a drop in the optimum operating voltage $U_{\mathrm{m}}$ and the output power $P$ while the open-circuit voltage $U_{\mathrm{oc}}$ and the short-circuit current $I_{\mathrm{sc}}$ basically remain unchanged. The drop magnitude of $U_{\mathrm{m}}$ is associated with the sum of the optimum operating voltages of the shadowed cell strings. Meanwhile, the shading positions of shadows 1,2 , and 4 are in the same cell string. The voltage at the optimal operating point $U_{\mathrm{m}}$ therefore decreases when the area of the shadow is larger than or equal to the area of a single cell. Based on the simulation results, the parameter computation formula of a PV array under shadowing conditions can be obtained as follows:

$$
\begin{aligned}
I_{\mathrm{sc}}^{\prime} & =I_{\mathrm{sc}}, \\
U_{\mathrm{oc}}^{\prime} & =U_{\mathrm{oc}}, \\
I_{\mathrm{m}}^{\prime} & =I_{\mathrm{m}}, \\
U_{\mathrm{m}}^{\prime} & =U_{\mathrm{m}}-u_{1} \cdot n_{1}, \\
P_{\mathrm{m}}^{\prime} & =I_{\mathrm{m}}^{\prime} \cdot U_{\mathrm{m}}^{\prime},
\end{aligned}
$$

where $I_{\mathrm{sc}}^{\prime}$ and $I_{\mathrm{m}}^{\prime}$ are the short-circuit current and the current at the optimal operating point of the array under the shadowing condition, respectively, $U_{\mathrm{oc}}^{\prime}$ and $U_{\mathrm{m}}^{\prime}$ are the open-circuit voltage and the voltage at the optimal operating point of the array under the shadowing condition, respectively, and $I_{\mathrm{sc}}$ and $I_{\mathrm{m}}$ are the short-circuited current and the current at the optimal operating point of the array in the absence of shading, respectively. From (5) and (7), we can obtain $U_{\mathrm{oc}}$ and $U_{\mathrm{m}}$ which are the open-circuit voltage and the voltage at the optimal operating point of the array in the absence of shading. We can obtain $u_{1}$ and $n_{1}$ from (6) and (8), where $u_{1}$ is the optimum operating voltage of the cell string and $n_{1}$ is the number of the shadowed cell strings.

Based on the above analysis, we can obtain the distribution rules of the electrical parameters of photovoltaic array under the following shadowing conditions:

(1) Local shadowing does not influence $U_{\mathrm{oc}}$ and $I_{\mathrm{sc}}$ of the photovoltaic array.

(2) $U_{m}$ drops when the area of the shadow in a cell string is larger than or equal to the area of a single cell. The drop intensity is proportional to the number of the shadowed cell strings and the optimum operating voltage of the cell tandem. The output power therefore decreases.

(3) In actual application, shadowing in photovoltaic array arises from structures such as the front and rear 


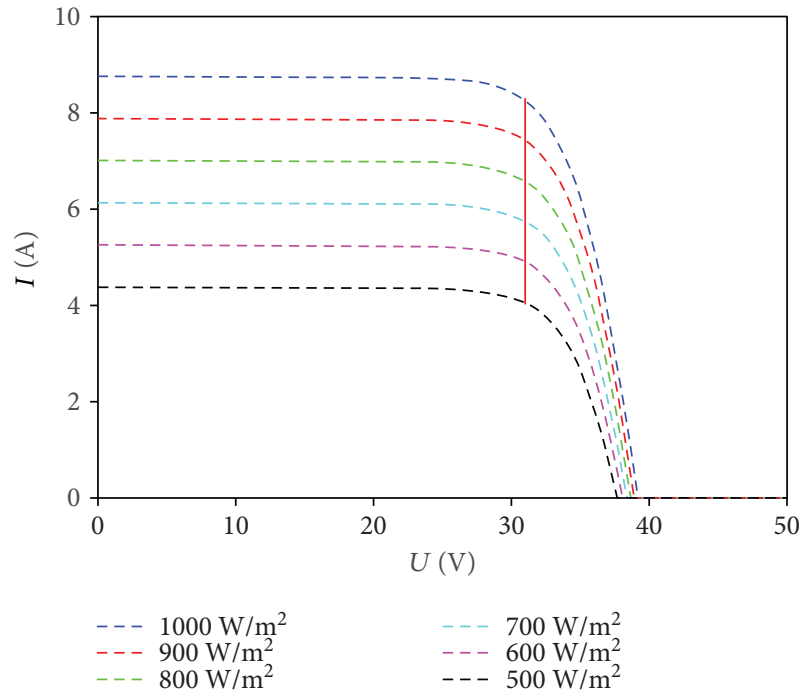

(a)

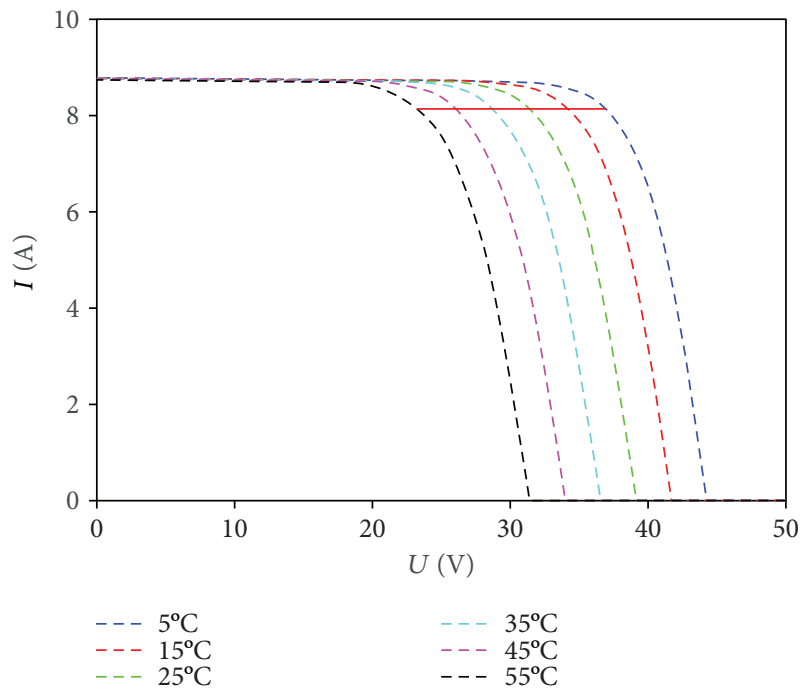

(c)

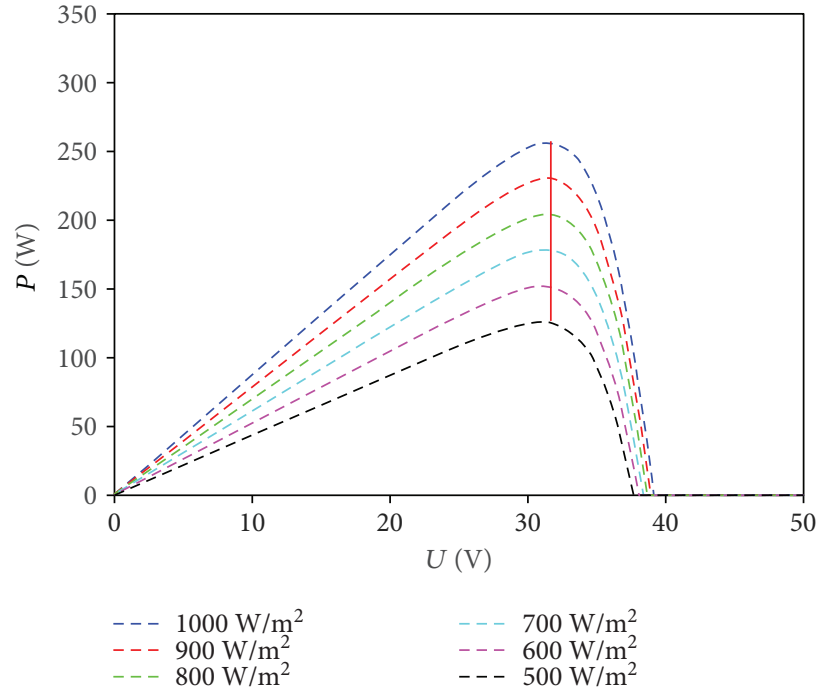

(b)

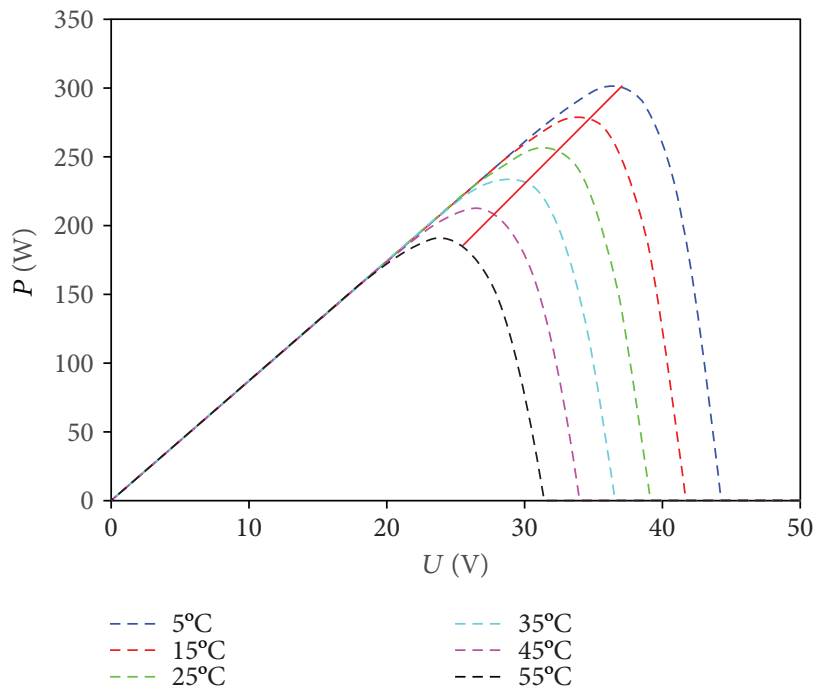

(d)

FIgure 6: (a) IV curve under different irradiances, (b) PV curve under different irradiances, (c) IV curve under different temperatures, (d) PV curve under different temperatures. Describing the IV and PV curves under different operating conditions.

rows of the array and tall buildings. The area of the shadow is generally larger than that of a single photovoltaic cell. The voltage effect on the array arising from a shadow with an area less than that of a single photovoltaic cell can be ignored.

3.2. Cover Shading. The simulation results under the cover conditions are shown in Figure 9. The bypass diode is usually in a nonconducting state, and the module output is normally under uniform light in the absence of covering. The cells will have negative voltage and trigger the conduction of bypass diode when the negative voltage reaches a certain upper limit. In Figure 9, the output characteristics have no multiple peaks due to the fact that the covered cells with negative voltage trigger the conduction of the corresponding bypass diode. Covers 1,2 , and 4 have consistent output characteristics. Similarly, covers 3 and 5 are consistent. The output decreases in a ladder pattern from cover 4 to cover 6 . In terms of the electrical parameters, $I_{\mathrm{sc}}$ and $I_{\mathrm{m}}$ remain unchanged while $U_{\mathrm{oc}}, U_{\mathrm{m}}$, and $P_{\mathrm{m}}$ decline regularly. The distribution of the electrical parameters of the array under cover shading is shown in Table 4.

Based on the above analysis, we can obtain the distribution rules of the electrical parameters of photovoltaic array under cover shading as follows:

(1) Cover shading does not influence $I_{\mathrm{sc}}$ and $I_{\mathrm{m}}$ of the photovoltaic array.

(2) $U_{\text {oc }}$ and $U_{\mathrm{m}}$ drop when the area of the covered portion within the cell string is larger than or equal 


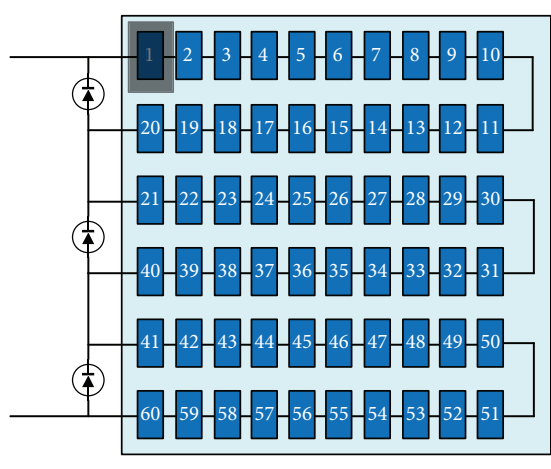

(a) Shadow/cover 1

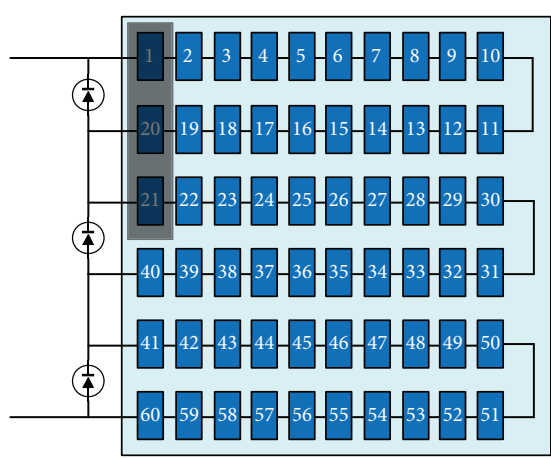

(c) Shadow/cover 3

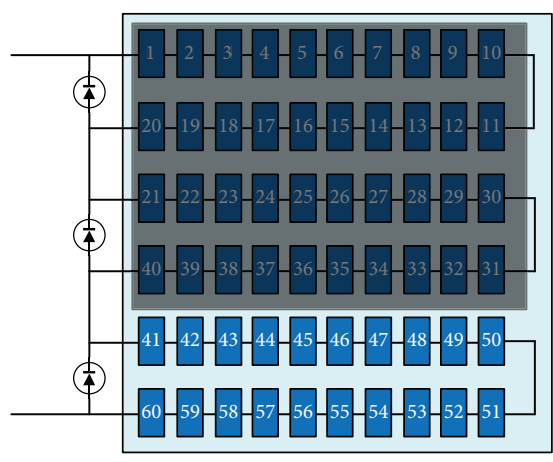

(e) Shadow/cover 5

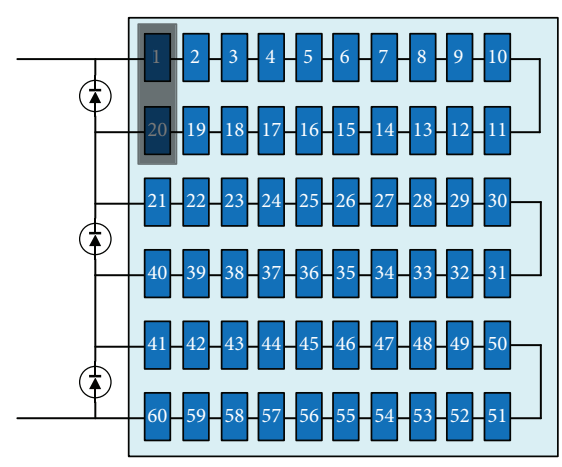

(b) Shadow/cover 2

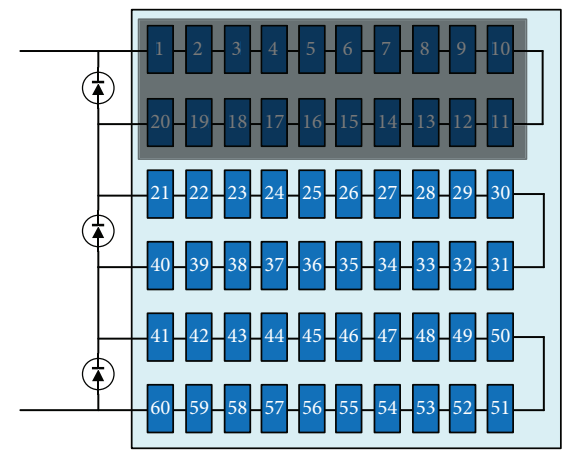

(d) Shadow/cover 4

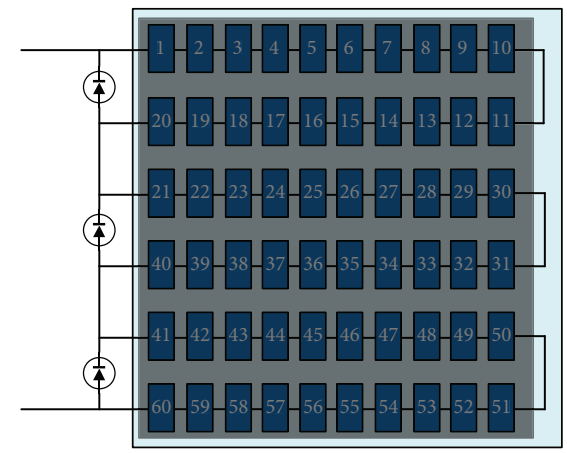

(f) Shadow/cover 6

Figure 7: Setting of different shading conditions. Shading one cell/cell string, two cells/cell strings, three cells/cell strings, respectively.

to the area of a single cell. The drop intensity is proportional to the number of the covered cell strings and the cell string voltage. The output power therefore decreases.

(3) Cover shading with an area less than that of a single cell can be considered negligible.

The computation formula of the electrical parameters of the array under cover shading is as follows:

$$
\begin{aligned}
I_{\mathrm{sc}}^{\prime} & =I_{\mathrm{sc}}, \\
U_{\mathrm{oc}}^{\prime} & =U_{\mathrm{oc}}-u_{2} \cdot n_{2}, \\
I_{\mathrm{m}}^{\prime} & =I_{\mathrm{m}}, \\
U_{\mathrm{m}}^{\prime} & =U_{\mathrm{m}}-u_{1} \cdot n_{2}, \\
P_{\mathrm{m}}^{\prime} & =I_{\mathrm{m}}^{\prime} \cdot U_{\mathrm{m}}^{\prime},
\end{aligned}
$$

TABLE 2: Setting of simulation conditions.

\begin{tabular}{lccc}
\hline $\begin{array}{l}\text { Type of } \\
\text { shading }\end{array}$ & $\begin{array}{c}\text { Solar irradiation } \\
\text { intensity of the } \\
\text { shaded portion } \\
\left(\mathrm{W} / \mathrm{m}^{2}\right)\end{array}$ & $\begin{array}{c}\text { Solar irradiation } \\
\text { intensity of the } \\
\text { unshaded portion } \\
\left(\mathrm{W} / \mathrm{m}^{2}\right)\end{array}$ & $\begin{array}{c}\text { Module } \\
\text { temperature } \\
\left({ }^{\circ} \mathrm{C}\right)\end{array}$ \\
\hline $\begin{array}{l}\text { Shadow } \\
\text { shading }\end{array}$ & 150 & 1000 & 25 \\
$\begin{array}{l}\text { Cover } \\
\text { shading }\end{array}$ & 0 & 1000 & 25 \\
\hline
\end{tabular}

The irradiation intensity of the shadowed photovoltaic cells is set at $15 \%$ of the irradiation intensity absorbed by the unshadowed modules. The solar irradiation intensity of cover is set at zero. Temperature is $25^{\circ} \mathrm{C}$.

where $n_{2}$ is the number of the covered cell strings under the covering condition and $u_{2}$ is the open-circuit voltage of the cell string. 

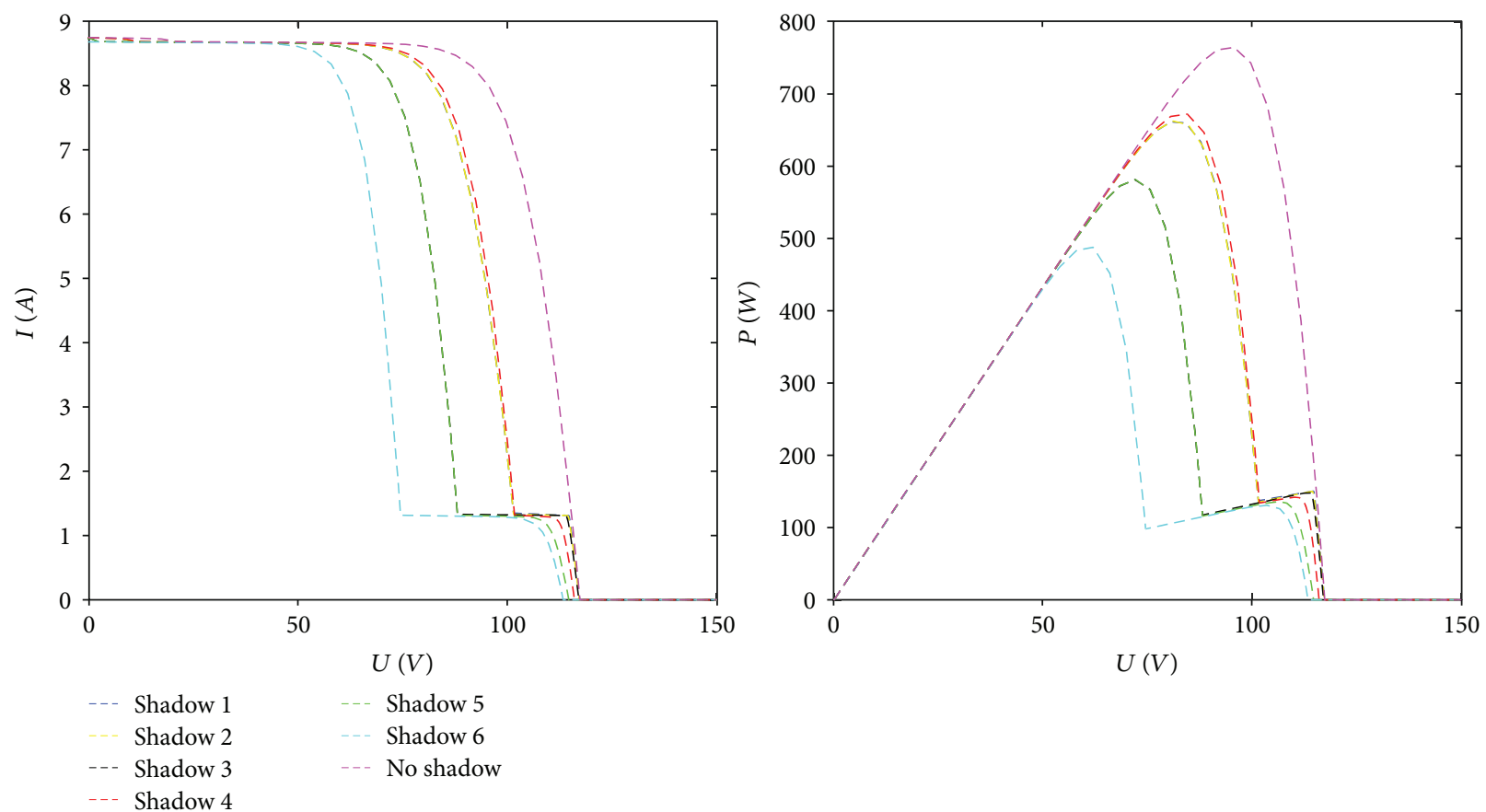

Figure 8: Simulation result for shadowing. Under the shadow conditions, the output curve presents a multipeak feature.

TABLE 3: Distribution of electrical parameters under shadowing condition.

\begin{tabular}{lccccc}
\hline Shadow conditions & $U_{\mathrm{oc}}(\mathrm{V})$ & $I_{\mathrm{sc}}(\mathrm{A})$ & $P(\mathrm{~W})$ & $U_{\mathrm{m}}(\mathrm{V})$ & $I_{\mathrm{m}}(\mathrm{A})$ \\
\hline Normal & 117.37 & 8.75 & 744.63 & 91.93 & 8.10 \\
Shadow 1 & 117.30 & 8.74 & 661.47 & 80.51 & 8.22 \\
Shadow 2 & 117.24 & 8.74 & 662.46 & 81.12 & 8.17 \\
Shadow 3 & 117.10 & 8.73 & 581.47 & 71.95 & 8.08 \\
Shadow 4 & 116.03 & 8.74 & 652.70 & 81.04 & 8.05 \\
Shadow 5 & 114.68 & 8.73 & 580.40 & 70.77 & 8.20 \\
Shadow 6 & 113.34 & 8.74 & 487.82 & 61.95 & 7.87 \\
\hline
\end{tabular}

The distribution of electrical parameters under different shading conditions.

3.3. Summary. To illustrate the distribution features of the electrical parameters of the photovoltaic array under different shading conditions, Figure 10 presents the IV and PV curves of the array under the two types of shading. Shadow 4, shadow 5, cover 4, and cover 5 are selected for comparison. The output features and parameter distribution rules of the photovoltaic array under the shadow and cover conditions are as follows:

(1) The output of the array under shadowing is characterized by multiple peaks and ladder pattern while cover shading has no such characteristics.

(2) Shadowing and covering have no effect on $I_{s c}$ of the array.

(3) When the shaded area is larger than or equal to a single cell, the shadow causes a drop in $U_{\mathrm{m}}$ while covering causes a drop in $U_{\mathrm{m}}$ and $U_{\mathrm{oc}}$. The voltage drop extent is associated with the number of the shaded cell strings and the string voltage. Any shading with an area less than that of a single cell is considered negligible.

(4) The difference between shadowing and covering conditions is whether $U_{o c}$ is falling or not. It can be judged from the distribution characteristics of $U_{\mathrm{m}}$ and $U_{\text {oc }}$.

\section{Empirical Validation of the Electrical Properties of Photovoltaic Array under Different Shading Conditions}

4.1. Method for Empirical Validation. Three modules were connected in series to create a photovoltaic array in the experiment. To investigate the distribution characteristics of the electrical parameters under different shading conditions, an opaque paperboard was used to set the shadow and covering conditions, respectively, as shown in Figure 7. The electrical parameters of the array under different shading conditions were recorded with an IV scanner. To explain the distribution rules of the electrical parameters, (8) was introduced to obtain the voltage at the maximum power point. Based on (11) and (12), we can obtain the voltage at the theoretical maximum power point under different shading conditions and compare with the experiment results. The experimental platform comprised of a photovoltaic array constituted by Jinko JKM245P modules, an irradiator for measuring the solar irradiance, a temperature sensor for measuring the 

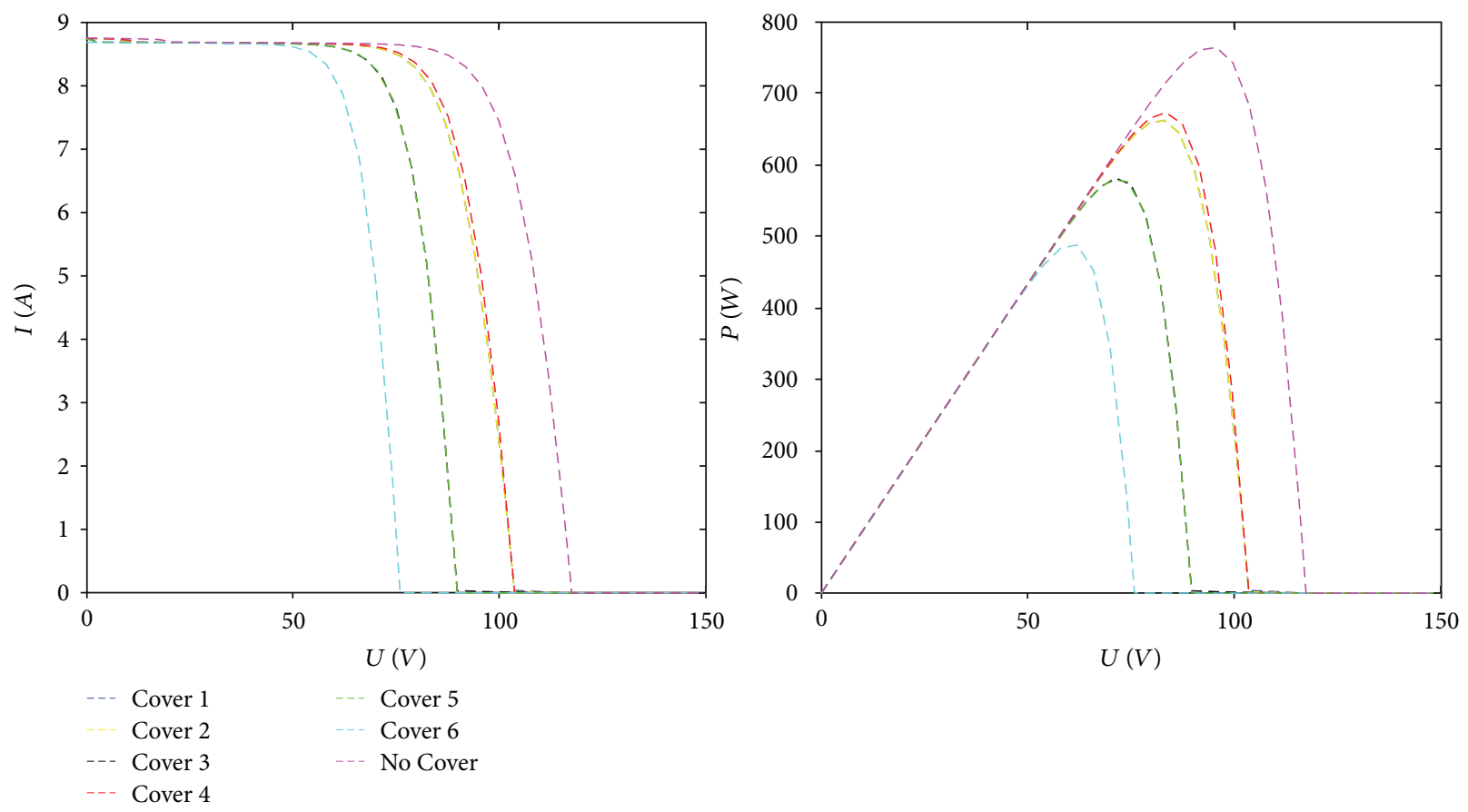

FIgURE 9: Simulation result for cover shading. The output curve without multipeak feature under cover shading.

TABLE 4: Distribution of electric parameters under cover shading.

\begin{tabular}{lccccc}
\hline Covering conditions & $U_{\mathrm{oc}}(\mathrm{V})$ & $I_{\mathrm{sc}}(\mathrm{A})$ & $P(\mathrm{~W})$ & $U_{\mathrm{m}}(\mathrm{V})$ & $I_{\mathrm{m}}(\mathrm{A})$ \\
\hline Normal & 117.37 & 8.75 & 743.97 & 91.11 & 8.17 \\
Cover 1 & 103.47 & 8.74 & 660.92 & 80.26 & 8.23 \\
Cover 2 & 103.50 & 8.74 & 662.99 & 82.39 & 8.05 \\
Cover 3 & 89.64 & 8.73 & 578.84 & 70.08 & 8.26 \\
Cover 4 & 103.44 & 8.74 & 652.07 & 81.90 & 7.96 \\
Cover 5 & 89.68 & 8.73 & 574.56 & 70.24 & 8.18 \\
Cover 6 & 75.83 & 8.69 & 489.36 & 60.99 & 8.02 \\
\hline
\end{tabular}

The distribution of electrical parameters under different cover conditions.

backboard temperature, and an IV tester. Figure 11 presents the structural diagram.

4.2. Analysis of the Empirical Testing Results. As seen in Figure 12, the results indicate that the output of the array under shadow is characterized by multiple peaks. Shadowing only influences the optimal operating voltage. According to (a) and (b), shadows 1 and 2 nearly have consistent output characteristics. Compared to the normal operating condition (nonshaded), the voltage at the optimal operating point moves left while the open-circuit voltage remains unchanged. The voltage at the optimal operating point further moves left in the case of shadow 3 compared to that in the case of shadow 2. According to (c) and (d), with the increase of the number of shaded cell strings, the voltage at the optimal operating point of the arrays decreases in sequence.
As seen in Figure 13, the results indicate that the output of the array under cover have no multiple peaks. According to (a) and (b), cover 1 and cover 2 have nearly consistent output characteristics. The voltage at the optimal operating point and the open-circuit voltage move left compared to the normal operating condition (noncovered). The bypass diode is thus activated when the area of the covering is larger than the area of a single cell. The voltage at the optimal operating point and the open-circuit voltage in the case of cover 3 move left compared with that in the case of cover 2. At this point, two bypass diodes are activated. According to (c) and (d), the voltage at the optimal operating point of the array and the open-circuit voltage decrease in sequence with the increase of the covered cell strings.

As seen in Figure 14, cover shading influences both the voltage at the maximum operating point $U_{\mathrm{m}}$ and the open-circuit voltage $U_{\text {oc }}$ while shadow shading only influences the voltage at the maximum operating point $U_{\mathrm{m}}$, which coincides with the simulation results.

Equations (11) and (12) present the computational formulae for the voltage at the optimal operating point and the open-circuit voltage $U_{o c}$ under the shadow and covering conditions, which will be analyzed in the following paragraphs. Under shading conditions, the relative error between the voltage at the theoretical optimal operating point and the voltage at the measured optimal operating point is expressed as $e_{1}$ and the relative error between the theoretical open-circuit voltage and the measured open-circuit voltage is expressed as $e_{2}$, as shown in (13). 

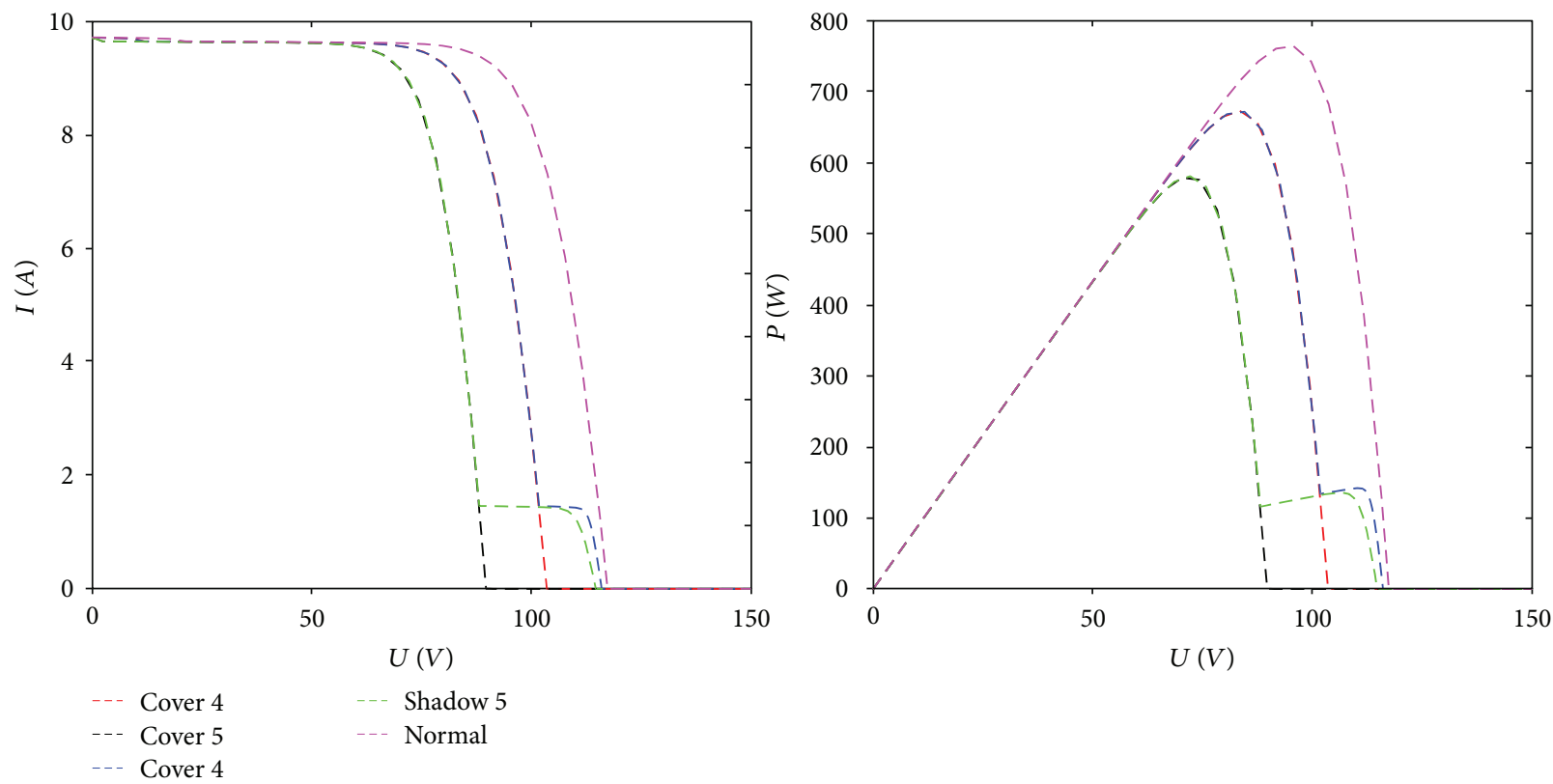

Figure 10: Comparison between shadow and cover conditions. The difference between shadow and cover is whether the open-circuit voltage drops or not.

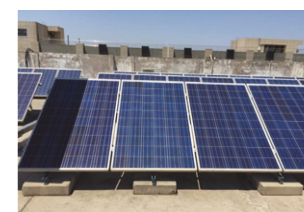

Shadow 1-shadow 6
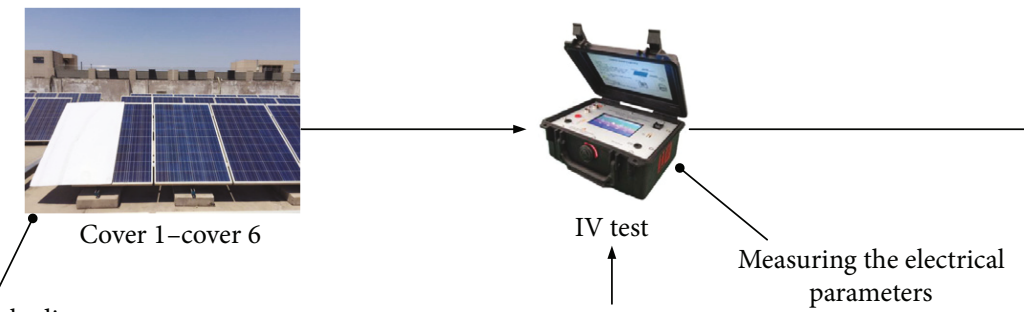

Different shading conditions

Calculating the theoretical value of electrical parameters

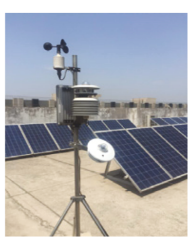

Radiation

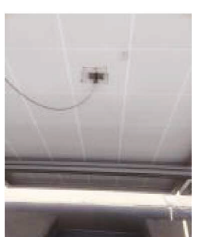

Temperature
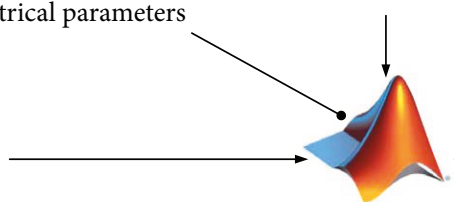

$U_{\mathrm{oc}}, U_{\mathrm{m}}, I_{\mathrm{sc}}, I_{\mathrm{m}}$

Theoretical calculating

FIGURE 11: Block diagram for experimental testing. By comparing the theoretical value and the measured value, summarize the rules.

$$
\begin{aligned}
& e_{1}=\frac{\left|U_{\mathrm{m} \text {-test }}^{\prime}-U_{\mathrm{m} \text {-calculate }}^{\prime}\right|}{U_{\mathrm{m} \text {-calculate }}^{\prime}} \times 100 \%, \\
& e_{2}=\frac{\left|U_{\mathrm{oc}-\text { test }}^{\prime}-U_{\mathrm{oc}-\text { calculate }}^{\prime}\right|}{U_{\text {oc-calculate }}^{\prime}} \times 100 \%,
\end{aligned}
$$

where $U_{\mathrm{m} \text {-test }}{ }^{\prime}$ and $U_{\text {oc-test }}{ }^{\prime}$ are the measured voltage at the optimal operating point and the open-circuit voltage under shading conditions, respectively, and $U_{\mathrm{m} \text {-calculate }}$ and
$U_{\text {oc-calculate }}$ are the theoretical voltage at the optimal operating point and the open-circuit voltage under the shading conditions.

Table 5 lists the distribution of the voltage at the optimal operating point and the open-circuit voltage under different shading conditions and the relative error between the measured shaded voltage and the computed shaded voltage. As seen in the table, the maximum error between the measured voltage and the computed voltage is less than $2 \%$ under shading conditions. The empirical results completely coincide with the simulation results. 


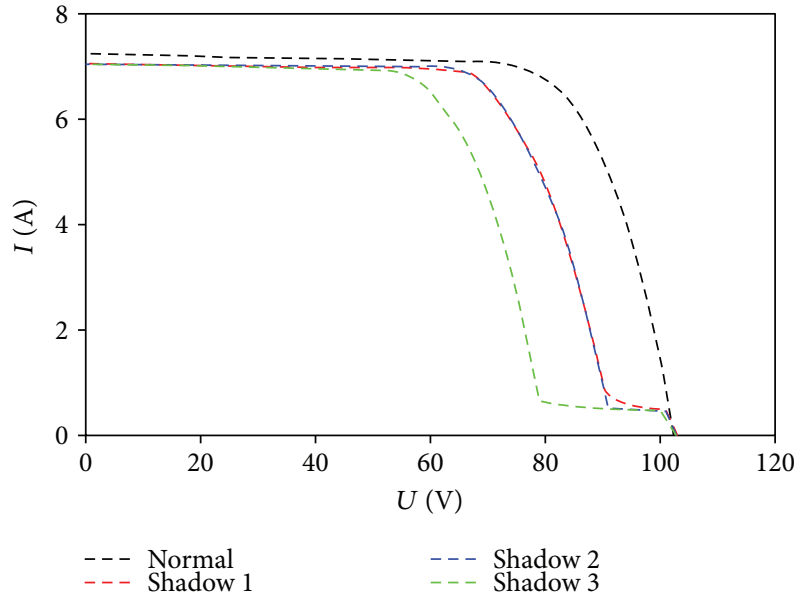

(a)

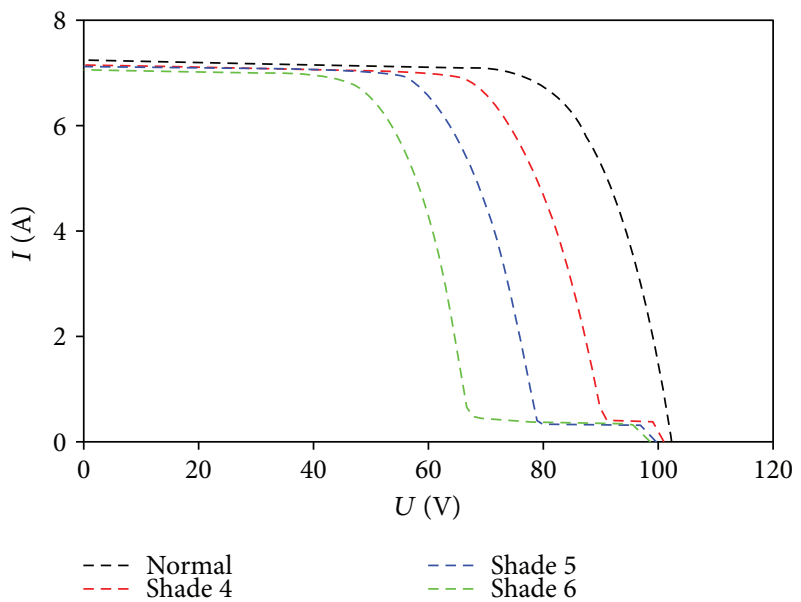

(c)

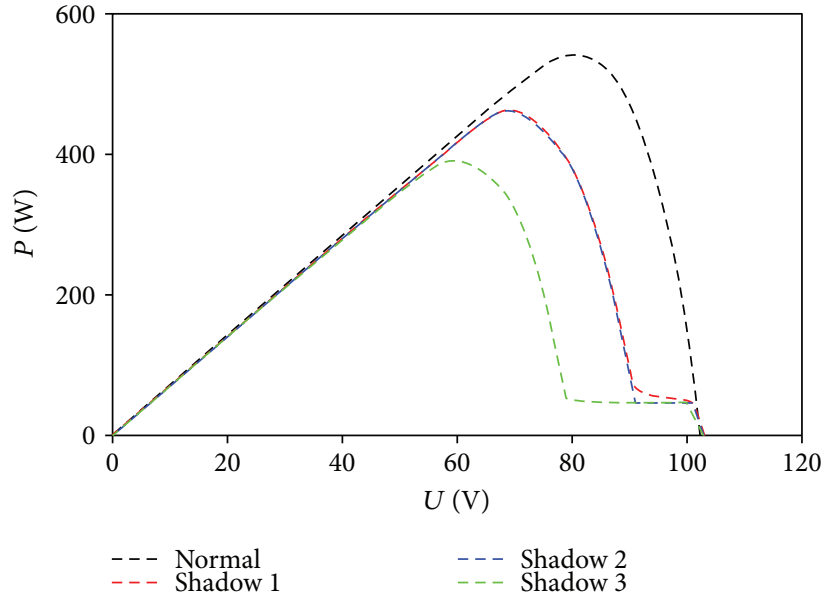

(b)

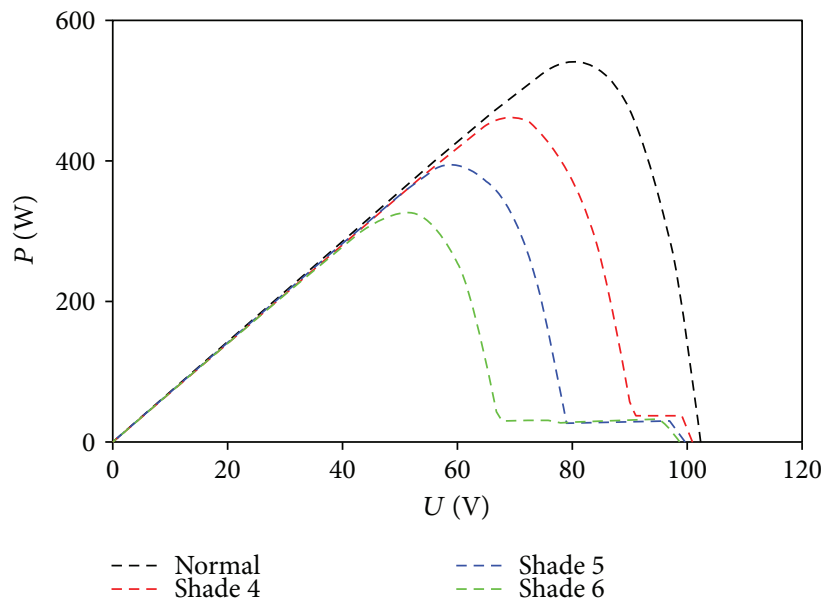

(d)

FIGURE 12: Results for the shadowing experiment. The curves are coincide with the simulation results.

\section{Based on Table 5, it can be concluded that}

(1) the computation results of the electrical parameters of the theoretical optimal operating point under the shading conditions are accurate and applicable,

(2) the number of the shaded modules can be known from the voltage at the theoretical optimal operating point and the voltage at the measured optimal operating point. The computation formula is as follows:

$$
n_{3}=\left|\frac{U_{\mathrm{m} \text {-calculate }}^{\prime}-U_{\mathrm{m} \text {-test }}^{\prime}}{u}\right| \text {, }
$$

where $u$ is the optimum operating voltage of a cell string and $n_{3}$ is the number of the shaded modules.

\section{Conclusion}

The paper illustrates the distribution rules of the electrical parameters of photovoltaic array under two types of shading conditions, shadow and cover shadings, both by simulation and empirical testing drawing several conclusions as below:

(1) Shadow and cover shadings have different effects on photovoltaic array in actual engineering. This model accurately reflects the output properties of the photovoltaic array under different shading conditions.

(2) Shadowing only influences the voltage at the optimal operating point of the array while covering influences both the open-circuit voltage and the voltage at the optimal operating point. The type of shading, that is, the shadow and cover can be judged from the distribution of the open-circuit voltage and the voltage at the optimal operating point. Shading does not influence the current of the array. 

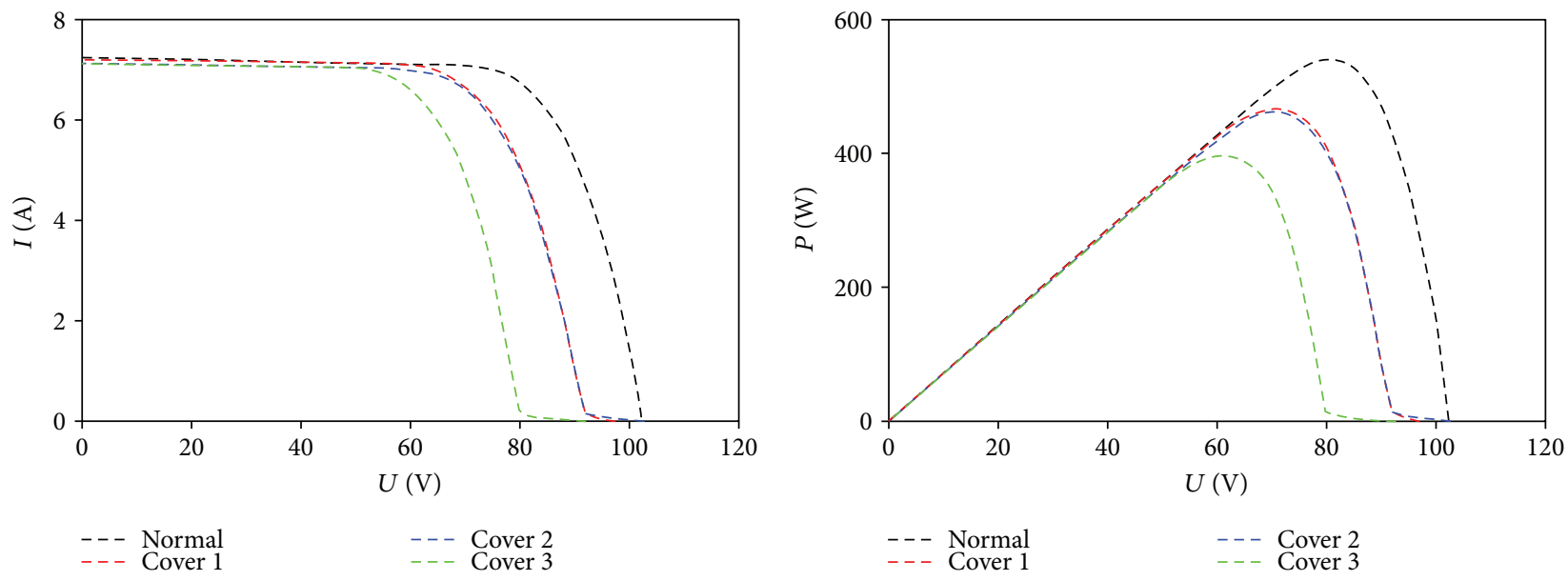

(a)

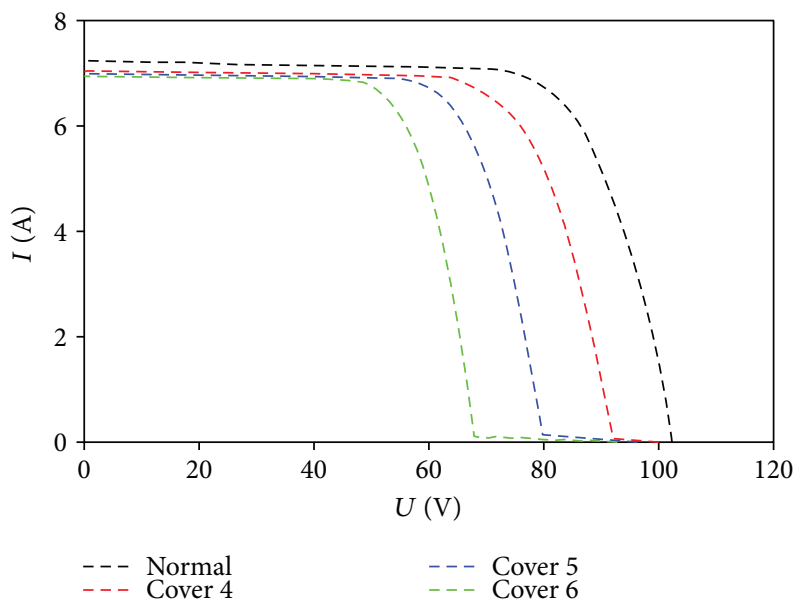

(c)

(b)

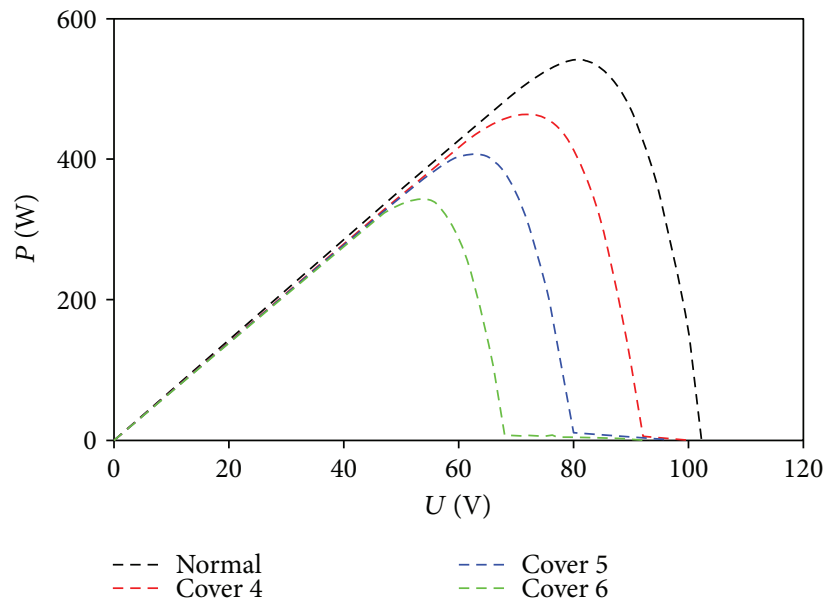

(d)

FIgURE 13: Results for the cover shading experiment. The curves are coincide with the simulation results.
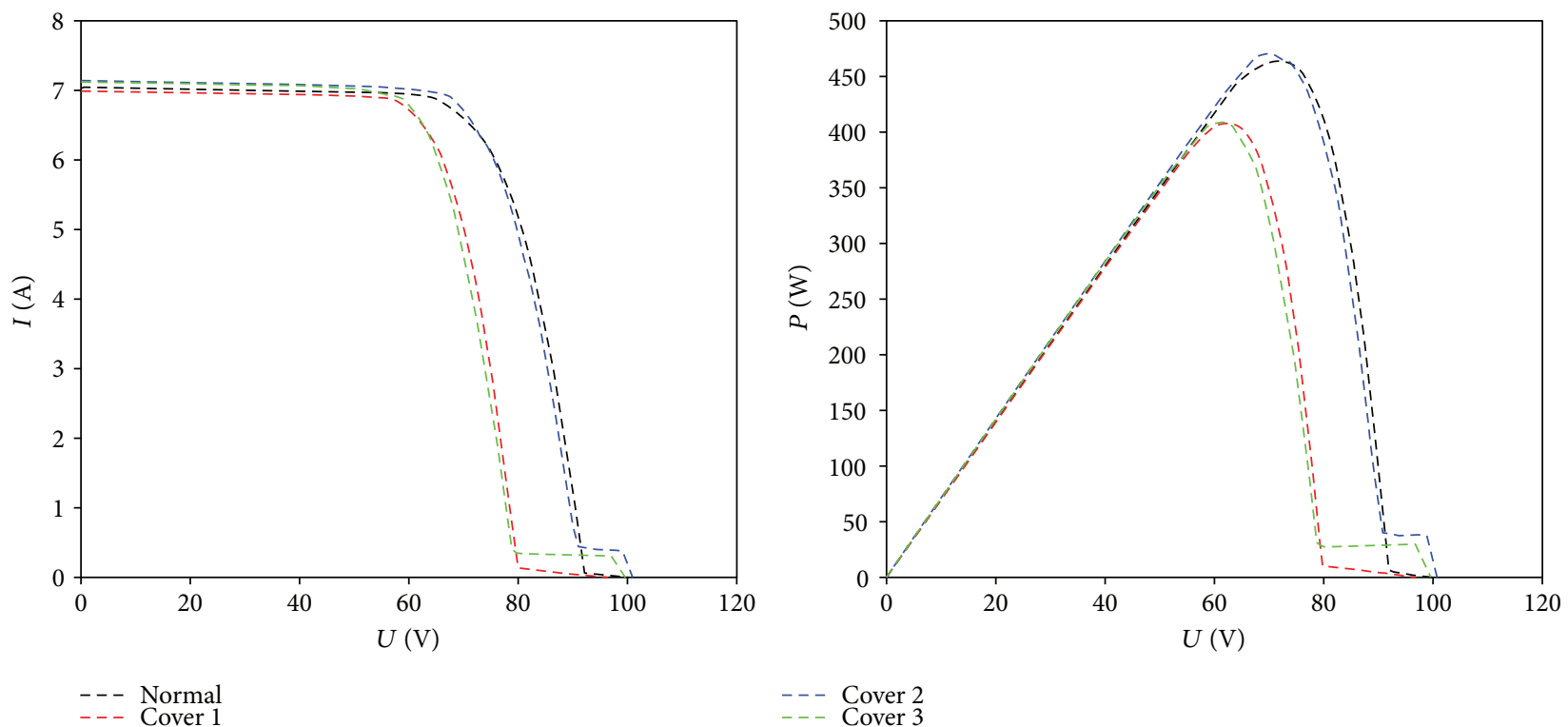

FIGURE 14: Comparison of the results of the shadow and the cover shading experiments. The difference between shadow and cover is whether the open-circuit voltage drops or not. 
TABLE 5: Error analysis for computation result.

\begin{tabular}{|c|c|c|c|c|c|c|c|c|}
\hline Shading type & $U_{\text {m-test }}^{\prime}(\mathrm{V})$ & $U_{\text {oc-test }}^{\prime}(\mathrm{V})$ & $U_{\text {m-calculate }}^{\prime}(\mathrm{V})$ & $U_{\text {oc-calculate }}^{\prime}(\mathrm{V})$ & $e_{1}(\%)$ & $e_{2}(\%)$ & $S\left(\mathrm{~W} / \mathrm{m}^{2}\right)$ & $T\left({ }^{\circ} \mathrm{C}\right)$ \\
\hline Normal & 87.0 & 108.4 & 88.2 & 109.8 & $1.3 \%$ & $1.3 \%$ & 982 & 36 \\
\hline Shadow 1 & 77.4 & 108.6 & 78.1 & 109.0 & $0.8 \%$ & $1.0 \%$ & 932 & 35 \\
\hline Shadow 2 & 77.2 & 108.5 & 78.1 & 109.3 & $1.1 \%$ & $1.1 \%$ & 936 & 35 \\
\hline Shadow 3 & 69.1 & 108.8 & 68.3 & 110.3 & $1.1 \%$ & $1.1 \%$ & 945 & 34 \\
\hline Shadow 4 & 76.5 & 108.4 & 77.9 & 109.6 & $1.7 \%$ & $1.0 \%$ & 931 & 36 \\
\hline Shadow 5 & 66.7 & 108.3 & 67.9 & 109.3 & $1.8 \%$ & $1.0 \%$ & 939 & 36 \\
\hline Shadow 6 & 57.4 & 108.3 & 57.9 & 109.1 & $0.8 \%$ & $1.1 \%$ & 936 & 36 \\
\hline Cover 1 & 77.1 & 97.4 & 78.1 & 97.81 & $1.3 \%$ & $0.4 \%$ & 973 & 36 \\
\hline Cover 2 & 77.6 & 96.1 & 78.3 & 98.03 & $0.9 \%$ & $1.9 \%$ & 973 & 35 \\
\hline Cover 3 & 68.1 & 87.1 & 68.4 & 86.08 & $0.3 \%$ & $1.1 \%$ & 952 & 34 \\
\hline Cover 4 & 77.8 & 98.3 & 78.5 & 98.23 & $0.8 \%$ & $0.1 \%$ & 942 & 33 \\
\hline Cover 5 & 67.9 & 83.8 & 68.3 & 85.25 & $0.5 \%$ & $1.7 \%$ & 963 & 35 \\
\hline Cover 6 & 58.6 & 74.2 & 58.1 & 73.69 & $0.9 \%$ & $0.6 \%$ & 959 & 36 \\
\hline
\end{tabular}

The data of shading voltage under different conditions and the relative error between the measured occlusion voltage and the theoretical occlusion voltage.

(3) A drop occurs in voltage when the area of shading in a cell string is larger than or equal to that of a single cell. The magnitude of the drop is proportional to the number of the shaded strings and the string voltage.

(4) The number of the shaded modules can be effectively judged from the computed results of the theoretical maximum power point and the measured results.

\section{Data Availability}

The data used to support the findings of this study are available from the corresponding author upon request.

\section{Conflicts of Interest}

The authors declare that they have no conflicts of interest.

\section{Acknowledgments}

This work was supported by the Fundamental Research Funds for the Central Universities (2016MS52, 2016MS31) and China Three Gorges New Energy Co. Ltd.

\section{References}

[1] P. Guerriero, F. Di Napoli, F. Cominale, V. d'Alessandro, and S. Daliento, "Accurate analysis of small shadows effects on photovoltaic systems yield," in 2014 International Symposium on Power Electronics, Electrical Drives, Automation and Motion, pp. 987-992, Ischia, Italy, June 2014.

[2] J. Qi, X. Zhang, Y. Zhang, and W. Zhou, "Study on simulation algorithm of PV array considering shade effect," Proceedings of the CSEE, vol. 32, pp. 131-138, 2012.

[3] C. H. Wu, D. Q. Zhou, and Z. H. Li, "Hot spot detection and fuzzy optimization control method of PV module," Proceedings of the CSEE, vol. 33, pp. 50-61, 2013.

[4] Y. Haoyuan, Y. Shuo, S.-C. Tan, and S. Y. R. Hui, "Dynamic modeling of partial shading on photovoltaic arrays," in 2015
IEEE Energy Conversion Congress and Exposition (ECCE), pp. 6616-6621, Montreal, QC, Canada, September 2015.

[5] K. Ding, X. G. Bian, and H. H. Liu, "Matlab-Simulink based modeling to study the influence of nonuniform insolation photovoltaic array," in 2011 Asia-Pacific Power and Energy Engineering Conference, pp. 1-4, Wuhan, China, March 2011.

[6] P. Burns and N. Anani, "Modelling and simulation of photovoltaic arrays under varying conditions," in 2014 9th International Symposium on Communication Systems, Networks \& Digital Sign (CSNDSP), pp. 831-834, Manchester, UK, July 2014.

[7] G. Celsa and G. M. Tina, "Matlab/Simulink model of photovoltaic modules/strings under uneven distribution of irradiance and temperature," in IREC'2015. The Sixth International Renewable Energy Congress, pp. 1-6, Sousse, Tunisia, March 2015.

[8] Q. Tian, Z. Zhao, Y. Deng, L. Yuan, and F. He, "Simulation and experimental study about reverse model of photovoltaic cells," Proceedings of the CSEE, vol. 31, no. 23, pp. 121-128, 2011.

[9] A. Kumar, R. K. Pachauri, and Y. K. Chauhan, "Experimental analysis of SP/TCT PV array configurations under partial shading conditions," in 2016 IEEE 1st International Conference on Power Electronics, Intelligent Control and Energy Systems (ICPEICES), pp. 1-6, Delhi, India, July 2016.

[10] F. Zhicheng, W. Yahui, and W. Lulu, "Experimental study on characteristics of PV module under partially shaded conditions," Acta Energiae Solaris Sinica, vol. 36, no. 2, pp. 392-398, 2015.

[11] T. P. Zhou and W. Sun, "Maximum power point tracking of photovoltaic array under nonuniform shadow conditions," Automation of Electric Power Systems, vol. 39, no. 10, pp. 4249, 2015.

[12] Y. P. Wang, X. B. Ruan, and Y. Li, "A rapid tracking method of maximum power point for solar units in series under uneven solar irradiance," Proceedings of the Chinese Society for Electrical Engineering, vol. 35, pp. 4870-4878, 2015.

[13] Y. W. Zhu, X. C. Shi, Y. Q. Dan et al., "Application of PSO algorithm in global MPPT for PV array," Proceedings of the CSEE, vol. 32, pp. 42-48, 2012.

[14] X. Yuan, D. Yang, and H. Liu, "MPPT of PV system under partial shading condition based on adaptive inertia weight particle 
swarm optimization algorithm," in 2015 IEEE International Conference on Cyber Technology in Automation, Control, and Intelligent Systems (CYBER), pp. 729-733, Shenyang, China, June 2015.

[15] X. Liu, F. Zhuo, Y. Chen, and L. Xiong, "Development of fast simulation models for photovoltaic generation system based on Simulink," in 2015 IEEE Energy Conversion Congress and Exposition (ECCE), pp. 3265-3270, Montreal, QC, Canada, September 2015.

[16] Y. J. Wang and S. S. Lin, "Analysis of a partially shaded PV array considering different module connection schemes and effects of bypass diodes," in 2011 International Conference \& Utility Exhibition on Power and Energy Systems: Issues and Prospects for Asia (ICUE), pp. 1-7, Pattaya City, Thailand, September 2011.

[17] D. Q. Zhou, C. H. Wu, Z. H. Li, L. Fu, and Y. Z. Wang, "Simulation and experimental study of the photovoltaic model under partial shading," Acta Energiae Solaris Sinica, vol. 35, pp. 2098-2105, 2014. 

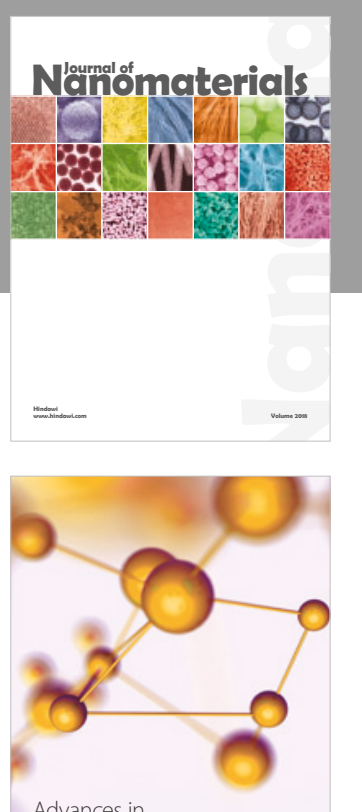

Physical Chemistry
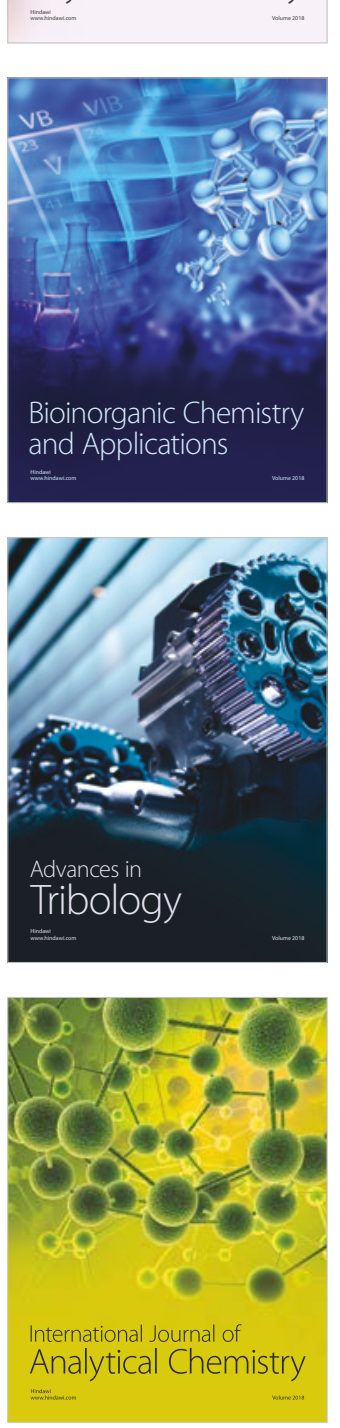

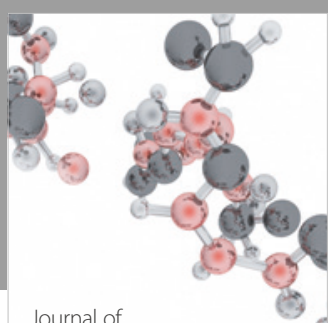

Analytical Methods

in Chemistry

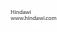

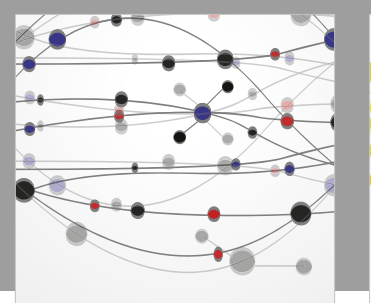

The Scientific World Journal

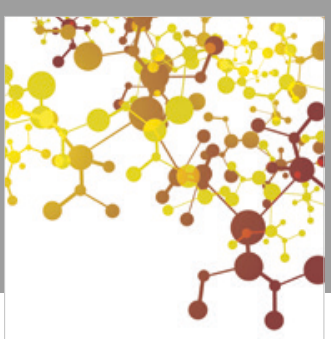

Journal of

Applied Chemistry
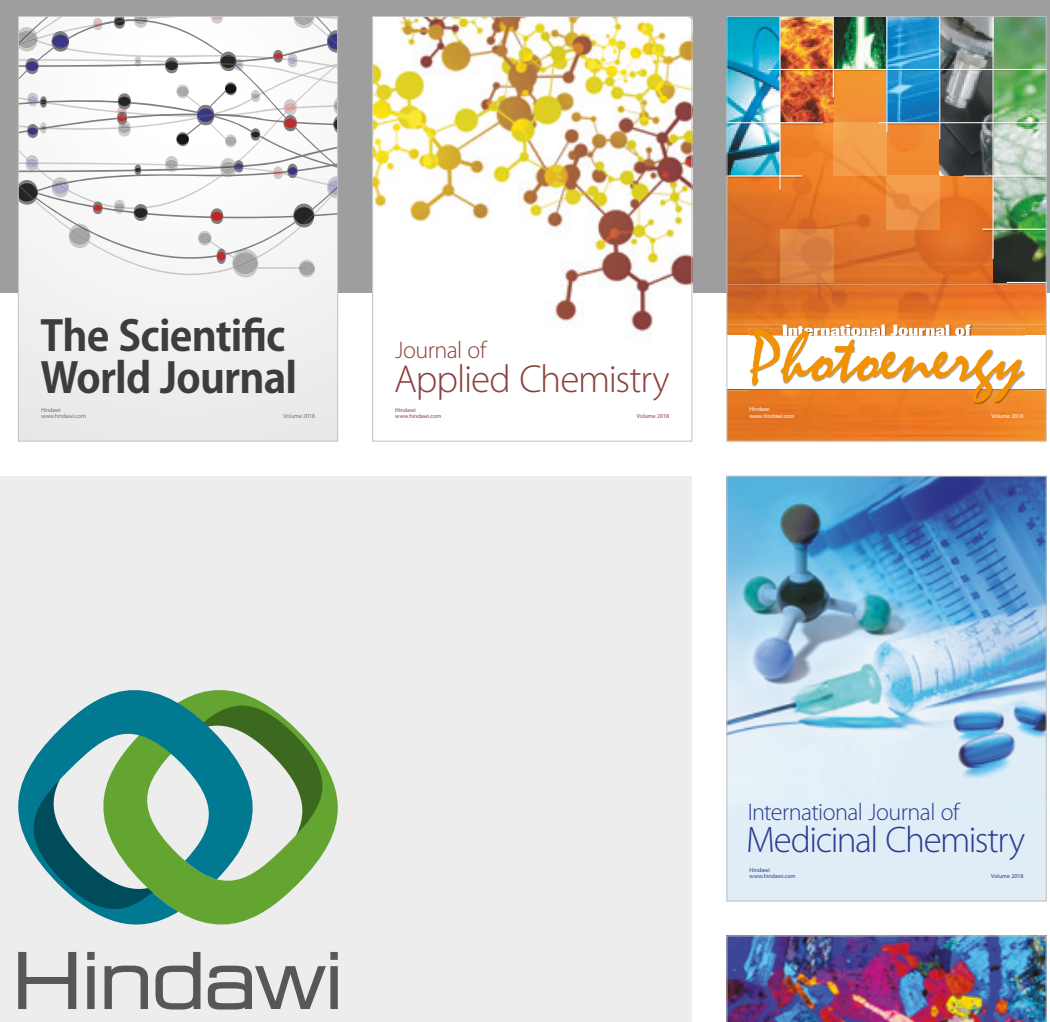

Submit your manuscripts at

www.hindawi.com
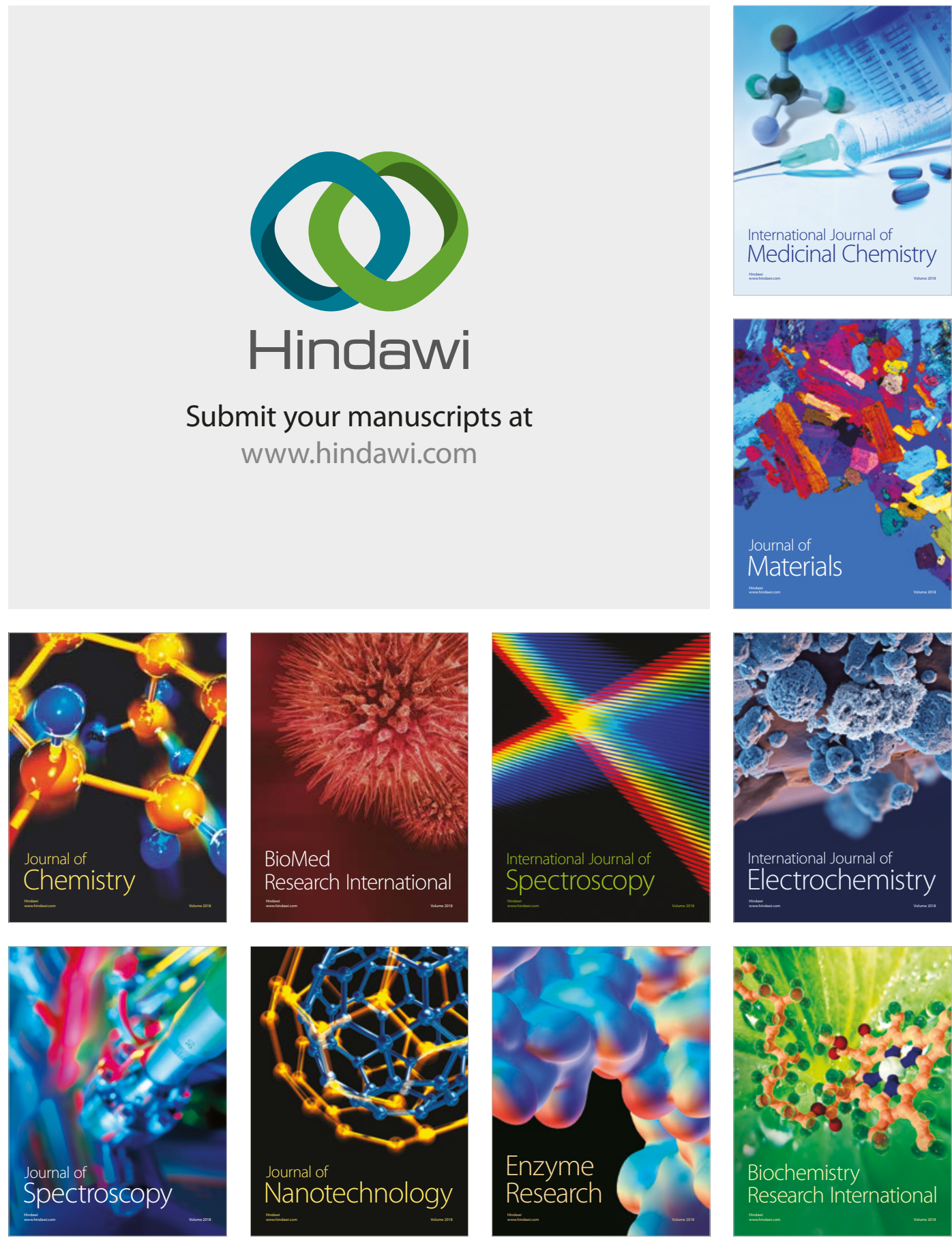
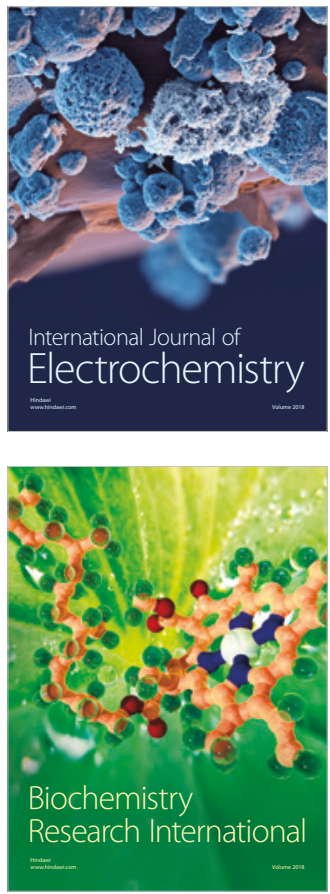